\title{
Impact of mandibular conventional denture and overdenture on quality of life and masticatory efficiency
}

Rachel Gomes CARDOSO(a) Laércio Almeida de MELO(a) Gustavo Augusto Seabra BARBOSA(a) Patrícia dos Santos CALDERON(a) Adriano Rocha GERMANO(a) Wilson MESTRINER JUNIOR ${ }^{(b)}$ Adriana da Fonte Porto CARREIRO(a)

(a) Universidade Federal do Rio Grande do Norte - UFRN, Department of Dentistry, Natal, Rio Grande do Norte, Brazil.

(b) Univesidade de Sao Paulo - USP, Department of Dentistry, Ribeirão Preto, São Paulo, Brazil

Declaration of Interests: The authors certify that they have no commercial or associative interest that represents a conflict of interest in connection with the manuscript.

\section{Corresponding Author:}

Laércio Almeida de Melo

E-mail: laercio_melo91@hotmail.com

DOI: 10.1590/1807-3107BOR-2016.vol30.0102

Submitted: Jul 24, 2015

Accepted for publication: May 11, 2016

Last revision: Jun 27, 2016

\begin{abstract}
The aim of this non-randomized controlled clinical trial was to evaluate the oral health-related quality of life and masticatory efficiency of patients rehabilitated with mandibular two-implant overdentures with immediate loading or conventional dentures. Fifty completely edentulous patients wearing bimaxillary conventional dentures, for at least one year, were recruited. The patients were then assigned to either two treatment groups: mandibular overdentures supported by two implants with bar-clip system and a maxillary conventional denture ( $\mathrm{n}=25)$, and new maxillary and mandibular conventional complete dentures $(n=25)$. Masticatory efficiency and oral health-related quality of life were assessed before and 3 months after denture insertion. The Brazilian version of OHIP-Edent questionnaire was used to assess the oral health-related quality of life. Masticatory efficiency was evaluated with chewing capsules through a colorimetric method. The results revealed fewer oral health-related quality of life problems in patients wearing mandibular two-implant overdentures compared to the conventional dentures group. In addition, the implant overdenture group presented statistically significant improvement in masticatory efficiency $(p=0.001)$. There was no correlation between masticatory efficiency and OHIP in the implant group ( $p>0.05)$, however a correlation was found in the conventional denture group ( $p<0.05)$. Therefore, these short-term results suggest that mandibular overdenture retained by 2 implants with immediate loading combined with maxillary conventional dentures provide better masticatory efficiency and oral health-related quality of life than mandibular conventional dentures.
\end{abstract}

Descriptors: Dental Implants; Quality of Life; Bite Force.

\section{Introduction}

Oral rehabilitation using a 2-implant overdenture (IOD) is a widely discussed topic. Current studies have recommended this treatment approach for the edentulous mandible. In addition to being a simple and low-cost alternative for implant rehabilitation, IOD also improves patient's satisfaction and quality of life, and enhances masticatory effectiveness/ability $1,2,3,4,5,6,7,8$.

During the last three decades, some questionnaires have been used to assess the impact of oral health on quality of life and daily activities of dental patients, such as the Oral Health Impact Profile (OHIP) ${ }^{9,10}$. 
The OHIP-Edent questionnaire is a simplified version of OHIP, specifically constructed for edentulous patients wearing complete dentures. However, only a few studies have used this questionnaire to compare the oral health-related quality of life among users of overdentures and conventional complete dentures ${ }^{11,12}$.

In a meta-analysis systematic review, the authors included 10 publications of 7 clinical trials comparing the effect of mandibular rehabilitation with conventional denture or implant-retained overdenture on satisfaction and oral health-related quality of life ${ }^{13}$. The authors concluded that, although the mandibular implant-supported overdenture was more satisfactory than conventional denture (CD), the treatment impact remains uncertain because the patient's preference about the type of rehabilitation was not taken into consideration and some patients that preferred rehabilitation with implants were randomly assigned to conventional dentures. Therefore, the experimental design might have been a source of bias in patients' satisfaction results and oral health-related quality of life. Furthermore, as only a few studies were found about this topic, the study lacked scientific evidence.

Although studies comparing the effects of mandibular IOD or CD on quality of life and masticatory efficiency have shown better results for IOD treatment, their small sample sizes may jeopardize generalizability of the findings ${ }^{6,7,8}$. In addition, the association between masticatory efficiency and oral health-related quality of life were not evaluated in those studies ${ }^{6,7,8}$.

Evaluation of masticatory efficiency and oral health-related quality of life provides information about patients' specific needs, which leads to better and more satisfying clinical options. In addition, the present study also evaluated rehabilitation with immediately loaded overdentures, and the inclusion of a control group provided an innovative experimental design. The aim of this non-randomized controlled clinical trial was to evaluate the oral health-related quality of life and masticatory efficiency of patients rehabilitated with mandibular IOD or $\mathrm{CD}$. The correlation between masticatory efficiency and OHIP before and after implant insertion was also investigated. The findings may be helpful in making clinical decisions about rehabilitation of mandibular edentulous patients with immediately loaded implant-supported overdentures.

\section{Methodology}

\section{Study design}

This within-subject trial was conducted at the Federal University of Rio Grande do Norte (UFRN) between January 2011 and April 2014. The study was approved by the institutional Ethics Committee (protocol number 326/2011). Figure 1 shows the study flow diagram.

\section{Participants}

Bimaxillary edentulous individuals wearing conventional CDs were recruited for this study. Patients were divided into two groups according to the type of prosthesis of their choice (CD and IOD): those satisfied with their CDs were rehabilitated with a new $C D$, at the Department of Dentistry of UFRN (CD group). On the other hand, those requesting implant-supported treatment were rehabilitated with new maxillary conventional dentures and immediately loaded mandibular IOD with bar-clip system, at the UFRN Extension Project (IOD group). Patients with systemic disorders that are risk factors for implant failure or with history of implant loss were excluded from this study ${ }^{14}$. The oral health-related quality of

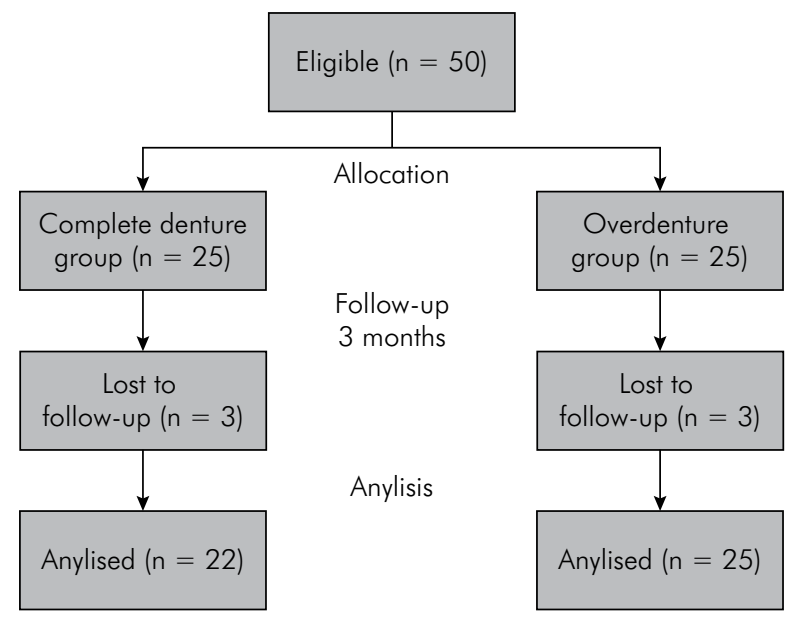

Figure 1. Study flow diagram. 
life and masticatory efficiency were evaluated in both groups before and three months after rehabilitation ${ }^{15}$.

\section{Treatment}

Patients were asked to sign an informed consent before the beginning of the study. Conventional maxillary and mandibular dentures were fabricated upon master casts obtained through functional impressions, with anatomically shaped acrylic resin teeth (Trilux, VIPI, Pirassununga, Brazil) and maximum extension of the denture base, using a standardized method that establishes a balanced occlusion. The individuals of the IOD group received initially maxillary and mandibular CDs. After 3 months, the mandibular denture was converted into an immediately loaded 2-implant overdenture. Two Neodent ${ }^{\circledR}$ Titamax implants (Neodent, Curitiba, Brazil; $3.75 \mathrm{~mm}$ in diameter; 9 or $11 \mathrm{~mm}$ in length) were inserted in the intraforaminal mandibular region. Custom surgical guides previously designed at the UFRN laboratory were used for precise placement of the dental implants. Antibiotics, analgesics and chlorhexidine mouth rinse were prescribed to the patients after implants insertion. Surgery and follow-ups were conduced according to the implant manufacturer's instructions, at the Department of Oral and Maxillofacial Surgery.

Masticatory efficiency and oral health-related quality of life were evaluated before treatment at both groups, 3 months after rehabilitation with new conventional dentures at $\mathrm{CD}$ group, and 3 months after insertion of new conventional maxillary denture and mandibular overdenture at IOD group.

\section{Measurements}

\section{Quality of life}

Quality of life was evaluated by applying the OHIP-Edent questionnaire for edentulous individuals, a simplified version of the Oral Health Impact Profile adapted for the Brazilian population by Souza et al ${ }^{15}$. This version consists of 19 questions divided into 7 subscales: handicap, social disability, psychological disability, physical disability, psychological discomfort, pain, and functional limitation. Each question has three possible answers, as follows: never (0); sometimes (1); or almost always (2). The total score of the OHIP-Edent ranges from 0 to 38 . Higher total scores represent greater impact of oral health on well-being and quality of life and also lower patient's satisfaction.

\section{Masticatory efficiency}

Objective evaluation of masticatory function was done using a colorimetric method ${ }^{16,17,18}$, with a capsuled artificial test-food. The test-food was obtained by ionotropic gelation of an aqueous dispersion of $2 \%$ pectin containing $50 \%$ solids and fuchsine in a $1.0 \mathrm{M}$ calcium chloride solution. After preparation, the beads were coated with a 5\% Eudragite solution (Eudragit E100) in a 10\% acetone solvent mixture in absolute ethanol. Soon after, $250 \mathrm{mg}$ of beads were packed in polyvinyl acetate capsules with $0.67 \mathrm{~mm}$ thick walls, an inner diameter of $7.6 \mathrm{~mm}$ and outer diameter of $8.95 \mathrm{~mm}$ and then sealed. Study individuals were instructed to normally chew the acetate capsules for $20 \mathrm{~s}$, while seated on a chair with both feet resting on the floor. Beads were then collected in a container and identified for subject and test number. The test was repeated twice. After, the content of the capsules was dissolved in $5 \mathrm{ml}$ of water by continuously mixing for $30 \mathrm{~s}$. The solution was then filtered through qualitative filter paper, and the extracted dye was quantified in the Beckman DU-640 UV-Visible Spectrophotometer (Beckman Inc., Palo Alto, CA, USA) at a visible light wavelength of $546 \mathrm{~nm}$. This method allowed measurement of masticatory efficiency based on extracted fuchsin concentration, which was expressed in absorbance (abs). The analysis of the beads was performed at the Biochemistry Laboratory of the UFRN.

\section{Statistical analysis}

Statistical analysis was performed using SPSS version 18.0 for Windows. One-sampleKolmogorov-Smirnov test was used to evaluate the normality of data distribution of all variables. The medians were compared since data were not normally distributed. The Mann-Whitney test was conducted to compare differences in medians of the OHIP-Edent and masticatory efficiency before and after treatment between groups. The Wilcoxon signed rank test was used for within group comparisons. Correlations between OHIP-Edent and masticatory efficiency was done with Spearman's correlation test. A $5 \%$ significance level $(p \leq 0.05)$ was used for all analyses. 


\section{Results}

Fifty edentulous subjects aged 44 to 75 years ( 9 men and 41 women; mean age 57.5 years) were included in the study. Twenty-five individuals (22 women and 3 men; mean age 57.2 years) were treated with maxillary CD and mandibular IOD with barclip system, and the other twenty-five patients (19 women and 6 men; mean age 57.8 years) were rehabilitated with new maxillary and mandibular CDs. Both groups were edentulous for similar number of years; 22.7 and 22.4 years, for IOD and CD groups, respectively. Age, gender or period of edentulism had no influence on the results of oral health-related quality of life and masticatory efficiency, in both groups.

In the IOD group, OHIP-Edent results showed statistically significant improvement in pain, psychological discomfort, physical disability, psychological disability and functional limitation subscales, after rehabilitation. The OHIP-Edent total score was also significantly lower $(p<0.001)$. However, in the CD group the difference between initial total score and total score after 3 months was not significant $(p=0.117)$, Except for the pain subscale that showed improvement over time $(p=0.003)$, all the other subscale scores were non-significant (Table 1).

A significant difference in masticatory efficiency was found between before and after rehabilitation with mandibular IOD ( $p<0.001)$. For the CD group, no significant difference was observed after 3 months $(\mathrm{p}=0.889)($ Table 2$)$

The impact of oral health on quality of life was significantly lower in the IOD group than in CD patients $(\mathrm{p}=0.001)$ (Table 3$)$.

Masticatory efficiency was significantly correlated with OHIP results in the CD group ( $p>0.05$ ). However, no correlation was found for the IOD group $(\mathrm{p}<0.05)($ Table 4$)$.

Table 1. OHIP-Edent subscores before and after conventional denture (CD) and implant overdenture (IOD); $Q u a r t i l e s\left(Q_{25}\right.$ and $\left.Q_{75}\right)$.

\begin{tabular}{|c|c|c|c|c|c|c|c|c|c|c|c|c|c|c|c|c|c|}
\hline \multirow{3}{*}{ Variable } & \multicolumn{8}{|c|}{ Conventional denture group (CD) } & \multirow{3}{*}{$p^{*}$} & \multicolumn{7}{|c|}{ Implant overdenture group (IOD) } & \multirow{3}{*}{ * } \\
\hline & \multicolumn{4}{|c|}{ Before } & \multicolumn{4}{|c|}{ After } & & \multicolumn{4}{|c|}{ Before } & \multicolumn{3}{|c|}{ After } & \\
\hline & $n$ & Median & $Q_{25}$ & $Q_{75}$ & $n$ & Median & $Q_{25}$ & $Q_{75}$ & & $\mathrm{n}$ & Median & $Q_{25}$ & $Q_{75}$ & Median & $Q_{25}$ & $Q_{75}$ & \\
\hline Functional limitation & 25 & 2.0 & 0.5 & 3.5 & 22 & 1.0 & 0.0 & 3.0 & 0.563 & 25 & 3.0 & 1.5 & 4.0 & 1.0 & 0.0 & 2.0 & 0.020 \\
\hline Pain & 25 & 2.0 & 0.0 & 4.0 & 22 & 0.0 & 0.0 & 1.25 & 0.003 & 25 & 2.0 & 1.0 & 4.0 & 0.0 & 0.0 & 1.0 & $<0.001$ \\
\hline $\begin{array}{l}\text { Psychological } \\
\text { discomfort }\end{array}$ & 25 & 0.0 & 0.0 & 0.0 & 22 & 0.0 & 0.0 & 1.0 & 0.059 & 25 & 0.0 & 0.0 & 1.5 & 0.0 & 0.0 & 0.0 & 0.004 \\
\hline Physical disability & 25 & 1.0 & 0.0 & 2.0 & 22 & 0.0 & 0.0 & 2.0 & 0.461 & 25 & .0 & 0.0 & 3.0 & 0.0 & 0.0 & 1.0 & 0.005 \\
\hline $\begin{array}{l}\text { Psychological } \\
\text { disability }\end{array}$ & 25 & 0.0 & 0.0 & 0.0 & 22 & 0.0 & 0.0 & 0.0 & 1.0 & 25 & 0.0 & 0.0 & 1.0 & 0.0 & 0.0 & 0.0 & 0.004 \\
\hline Social disability & 25 & 0.0 & 0.0 & 0.0 & 22 & 0.0 & 0.0 & 0.0 & 317 & 25 & 0.0 & 0.0 & 0.0 & 0.0 & 0.0 & 0.0 & 0.180 \\
\hline Handicap & 25 & 0.0 & 0.0 & 0.0 & 22 & 0.0 & 0.0 & 0.0 & 0.180 & 25 & 0.0 & 0.0 & 0 & 0.0 & 0.0 & 0.0 & 0.059 \\
\hline Total OHIP & 25 & 5.0 & 1.5 & 10.0 & 22 & 2.0 & 0.0 & 7.0 & 0.117 & 25 & 9.0 & 4.5 & 13.0 & 2.0 & 1.0 & 3.0 & $<0.001$ \\
\hline
\end{tabular}

*Wilcoxon test.

Table 2. Masticatory efficiency before and after three months of rehabilitation.

\begin{tabular}{lccccccc}
\hline Treatment & $N$ & Median & $Q_{25}$ & $Q_{75}$ & $L L$ & $U L$ & $p^{*}$ \\
\hline Conventional denture group before rehabilitation & 22 & 0.06250 & 0.04175 & 0.09975 & 0.014 & 0.286 & $p=0.889$ \\
Conventional denture group after rehabilitation & 22 & 0.06450 & 0.04500 & 0.09050 & 0.014 & 0.796 & 0.313 \\
Implant overdenture group before rehabilitation & 25 & 0.045 & 0.01550 & 0.09000 & 0.001 & 0.001 \\
Implant overdenture group after rehabilitation & 25 & 0.08400 & 0.05700 & 0.24650 & 0.004 & 0.436 & \\
\hline
\end{tabular}

LL: lower limit; UL: upper limit (95\% confidence interval); Quartiles $\left(Q_{25}\right.$ and $\left.Q_{75}\right)$; ${ }^{*}$ Wilcoxon test. 
Table 3. OHIP-Edent scores and masticatory efficiency before and after treatment for the conventional denture (CD) and implant overdenture (IOD) groups.

\begin{tabular}{|c|c|c|c|c|c|c|c|}
\hline \multirow{2}{*}{ Variable } & \multicolumn{3}{|c|}{ CD group } & \multicolumn{4}{|c|}{ IOD group } \\
\hline & Median & $Q_{25}-Q_{75}$ & $\mathrm{LL}-\mathrm{UL}$ & Median & $Q_{25-} Q_{75}$ & $\mathrm{LL}-\mathrm{UL}$ & $p^{*}$ \\
\hline \multicolumn{8}{|l|}{ OHIP-Edent } \\
\hline Before treatment & 5.0 & $1.5-10.0$ & $0.0-38.0$ & 9.0 & $4.5-13.0$ & $0.0-21.0$ & \multirow{2}{*}{0.001} \\
\hline After treatment & 2.0 & $0.0-7.0$ & $0.0-34.0$ & 2.0 & $1.0-3.0$ & $0.0-9.0$ & \\
\hline \multicolumn{8}{|c|}{ Masticatory efficiency } \\
\hline Before treatment & 0.063 & $0.042-0.100$ & $0.014-0.29$ & 0.045 & $0.016-0.090$ & $0.001-0.313$ & \multirow[b]{2}{*}{0.00} \\
\hline After treatment & 0.065 & $0.045-0.090$ & $0.014-0.80$ & 0.084 & $\begin{array}{l}0.057- \\
0.0247\end{array}$ & $0.004-0.436$ & \\
\hline
\end{tabular}

LL: lower limit; UL: upper limit (95\% confidence interval); Quartiles $\left(Q_{25}\right.$ and $\left.Q_{75}\right)$; ${ }^{*}$ Mann-Whitney test

Table 4. Correlation between OHIP-Edent and masticatory efficiency before and after three months rehabilitation.

\begin{tabular}{|c|c|c|c|c|c|c|}
\hline \multirow{2}{*}{ Variable } & \multicolumn{3}{|c|}{ Conventional denture group } & \multicolumn{3}{|c|}{ Implant overdenture group } \\
\hline & $\mathrm{n}$ & Before & After & $\mathrm{n}$ & Before & After \\
\hline Spearman Correlation test & \multirow{2}{*}{22} & 0.49 & -0.446 & \multirow{2}{*}{25} & 0.247 & -0.128 \\
\hline$p$ & & 0.827 & 0.037 & & 0.234 & 0.543 \\
\hline
\end{tabular}

\section{Discussion}

This non-randomized controlled clinical trial analyzed the effect of mandibular CD and IOD with bar-clip system on patients' quality of life and masticatory efficiency. In the IOD group, a mandibular CD was converted into an implant-supported overdenture, after a plastic bar-clip system was fabricated for implants splinting. This technique is recommended as a simple and less time-consuming approach ${ }^{1}$. Masticatory efficiency and oral health-related quality of life were evaluated before and 3 months after insertion of the new dentures in both groups.

The higher prevalence of female patients in both groups confirms that women are usually more concerned about oral health and look for health services more frequently than men $^{19}$. In addition, this study showed significant improvement in oral health-related quality of life 3 months after insertion of implant-supported overdenture. In the CD group, there was no significant difference in oral health-related quality of life after rehabilitation with new CDs. Comparing both groups, IOD patients presented statistically better oral health-related quality of life than CD patients. The results of this study are in agreement with the literature ${ }^{1-5}$. Some clinical trials have reported reduced total OHIP score when a conventional denture was replaced by an overdenture, which means that this type of rehabilitation improves oral health-related quality of life $\mathrm{e}^{1-5}$. This study measured the oral health-related quality of life through the OHIP-Edent because it is more appropriate for complete edentulous patients than OHIP-1420.

These results also confirm that prosthesis retention is extremely important for patient's satisfaction ${ }^{21}$. Loss of retention and stability with mandibular CDs usually causes discomfort and functional limitation, which consequently impacts the oral health-related quality of life in a negative way ${ }^{21,22}$. Studies have shown that when mandibular CDs are converted into IOD, the masticatory effectiveness/ability increases and then satisfaction and quality of life improve $\mathrm{e}^{1,2,3,4,5,6,7,8}$.

The literature reports that $\mathrm{CD}$ wearers frequently exhibit poor masticatory efficiency ${ }^{21,22}$. The results of the present study are in agreement with those reports, as lower masticatory efficiency was found in the CD group than in the IOD group. Moreover, although new conventional dentures were fabricated for the $C D$ group, there was no difference in masticatory efficiency in relation to 
their old conventional prostheses. On the other hand, patients from the IOD group had a significant improvement in masticatory efficiency 3 months after insertion of overdentures. As the conversion of CDs into IODs have been shown to improve prostheses retention and stability ${ }^{21,22}$, it is suggested that masticatory performance is closely linked to denture retention and stability. Thus, with better retention and stability of prostheses, masticatory performance tends to increase.

In the present study, gender, age, and period of edentulism did not influence the OHIP-Edent score and masticatory efficiency in both groups. No correlation between oral health-related quality of life and masticatory efficiency was observed in IOD group. Therefore, additional factors are probably related to the present results, such as masticatory force, psychological and personal characteristics, and patient's satisfaction ${ }^{21,23,24,25}$.

Although the mandibular rehabilitation with implants may be advantageous in comparison to conventional dentures, other intrinsic factors are important for treatment success. The masticatory efficiency and performance depend on the relationship between elevator muscles, bite force, food texture and food amount for each masticatory cycle ${ }^{26}$.

This study considered the patient's preferences for the decision about the choice of treatment. In a meta-analysis systematic review evaluating the effect of mandibular rehabilitation with CDs and IODs on satisfaction and oral health-related quality of life, the authors concluded that, although rehabilitation with implants has been usually associated with better satisfaction and oral health-related quality of life, the impact of implant treatment on these variables is

\section{References}

1. Müller F, Duvernay E, Loup A, Vazquez L, Herrmann FR, Schimmel M. Implant-supported mandibular overdentures in very old adults: a randomized controlled trial. J Dent Res. 2013;92(12 Suppl):154S-60. doi:10.1177/0022034513509630

2. Heydecke G, Locker D, Awad MA, Lund JP, Feine JS. Oral and general health-related quality of life with conventional and implant dentures. Community Dent Oral Epidemiol. 2003;31(3):161-8. doi:10.1034/j.1600-0528.2003.00029.x uncertain. Patient's choice about type of rehabilitation was not taken into consideration, which probably caused the inclusion of bias $^{13}$. The treatment preference is one of the difficulties in randomized controlled clinical trials with implant-supported prostheses ${ }^{27}$. The patients who's preference is for implant rehabilitation will usually report disappointment if they are selected for the control group. In randomized studies, the loss of patients in the control group influences the results, since patient's preference is important for treatment acceptance.

In the present study, sample size was small but in accordance with previous trials with similar purpose and methods $\mathrm{s}^{1,7,8,14,17}$. In addition, the sample size of this study was calculated based on a difference between groups of up to 3 points in OHIP score and up to 0.06 abs in masticatory efficiency. This calculation was made using the OpenEpi calculator ${ }^{28}$.

Considering rehabilitation with IODs, further long-term controlled clinical studies are required to evaluate the effect of treatment on oral healthrelated quality of life and masticatory efficiency. Bone resorption in the posterior region and complications such as prosthesis fracture, loss of clip retention and tooth wear should be also evaluated ${ }^{29}$. Finally, the evaluation of the positive and negative impacts of this treatment in a long-term study, are also necessary.

\section{Conclusions}

The results of this study suggest that treatment with immediately loaded 2-implant mandibular overdenture associated with maxillary conventional denture provides better masticatory efficiency and oral health-related quality of life than upper and lower conventional dentures.
3. Heydecke G, Thomason JM, Lund JP, Feine JS. The impact of conventional and implant supported prostheses on social and sexual activities in edentulous adults. J Dent. 2005;33(8):649-57. doi:10.1016/j.jdent.2005.01.003

4. Allen PF, Thomason JM, Jepson NJA, Nohl F, Smith DG, Ellis J. A randomized controlled trial of implant-retained mandibular overdentures. J Dent Res. 2006;85(6):547-51. doi:10.1177/154405910608500613 
5. Kleis WK, Kämmerer PW, Hartmann S, Al-Nawas B, Wagner W. Comparison of three different attachment systems for mandibular two-implant. overdentures: one-year report. Clin Implant Dent Relat Res. 2010;12(3):209-18. doi:10.1111/j.1708-8208.2009.00154.x

6. Borges TF, Mendes FA, Oliveira TR, Gomes VL, Prado CJ, Neves FD. Mandibular overdentures with immediate loading: satisfaction and quality of life. Int J Prosthodont. 2011;24(6):534-9.

7. Kampen FMC, Bilt A, Cune MS, Fontijn-Tekamp FA, Bosman F. Masticatory function with implant-supported overdentures. J Dent Res. 2004;83(9):708-11. doi:10.1177/154405910408300910

8. Borges TF, Mendes FA, Oliveira TR, Prado CJ, Neves FD. Overdenture with immediate load: mastication and nutrition. Br J Nutr. 2011;105(7):990-4. doi:10.1017/S000711451000471X

9. Preciado A, Del Río J, Suárez-García MJ, Montero J, Lynch CD, Castillo-Oyagüe R. Differences in impact of patient and prosthetic characteristics on oral health-related quality of life among implant-retained overdenture wearers. J Dent. 2012;40(10):857-65. doi:10.1016/j.jdent.2012.07.006

10. Slade GD. Derivation and validation of a short-form oral health impact profile. Community Dent Oral Epidemiol. 1997;25(4):284-90. doi:10.1111/j.1600-0528.1997.tb00941.x

11. Zani SR, Rivaldo EG, Frasca LC, Caye LF. Oral health impact profile and prosthetic condition in edentulous patients rehabilitated with implant-supported overdentures and fixed prostheses. J Oral Sci. 2009;51(4):535-43. doi:10.2334/josnusd.51.535

12. Emami E, Heydecke G, Rompré PH, de Grandmont $P$, Feine JS. Impact of implant support for mandibular dentures on satisfaction, oral and general health-related quality of life: a meta-analysis of randomized-controlled trials. Clin Oral Implants Res. 2009;20(6):533-44. doi:10.1111/j.1600-0501.2008.01693.x

13. Fueki K, Kimoto K, Ogawa T, Garrett NR. Effect of implant-supported or retained dentures on masticatory performance: a systematic review. J Prosthet Dent. 2007;98(6):470-7. doi:10.1016/S0022-3913(07)60147-4

14. Buser D, Wismeijer D, Belser U. ITI treatment guide. 3th ed. Chicago: Quintessence; 2003.

15. Souza RF, Patrocínio L, Pero AC, Marra J, Compagnoni MA. Reliability and validation of a Brazilian version of the Oral Health Impact Profile for assessing edentulous subjects. J Oral Rehabil. 2007;34(11):821-6. doi:10.1111/j.1365-2842.2007.01749.x

16. Santos CE, Freitas O, Spadaro ACC, Mestriner-Junior W. Development of a colorimetric system for evaluation of the masticatory efficiency. Braz Dent J. 2006;17(2):95-9. doi:10.1590/S0103-64402006000200002
17. Ribeiro JA, Resende CM, Lopes AL, Mestriner WJ, Roncalli AG, Farias-Neto A et al. Evaluation of complete denture quality and masticatory efficiency in denture wearers. Int J Prosthodont. 2012;25(6):625-30.

18. Farias Neto A, Pereira BM, Xitara RL, Germano AR, Ribeiro JA, Mestriner Junior $\mathrm{W}$ et al. The influence of mandibular implant-retained overdentures in masticatory efficiency. Gerodontology. 2012;29(2):650-5. doi:10.1111/j.1741-2358.2011.00539.x

19. Nóbrega LM, Temóteo LM, Dias JN, Lima MMSM, Cavalcanti SDLB. Perception of oral health by patients who use dental clinics. Rev Odontol UNESP. 2013;42(4):259-65. doi:10.1590/S1807-25772013000400005

20. Allen PF, Locker D. A modified short version of the oral health impact profile for assessing health-related quality of life in edentulous adults. Int J Prosthodont. 2002;15(5):446-50.

21. Fontijn-Tekamp FA, Slagter AP, Van Der Bilt A, Van 'T Hof MA, Witter DJ, Kalk W et al. Biting and chewing in overdentures, full dentures, and natural dentitions. J Dent Res 2000;79(7):1519-24. doi:10.1177/00220345000790071501

22. Kapur KK, Soman SD. Masticatory performance and efficiency in denture wearers. J Prosthet Dent. 2006;95(6):407-11. doi:10.1016/j.prosdent.2006.03.012

23. Rismanchian M, Bajoghli F, Mostajeran Z, Fazel A, Eshkevari P. Effect of implants on maximum bite force in edentulous patients. J Oral Implantol. 2009;35(4):196-200. doi:10.1563/1548-1336-35.4.196

24. Emami E, Allison PJ, Grandmont P, Rompré PH, Feine JS. Better oral health related quality of life: type of prosthesis or psychological robustness? J Dent. 2010;38(3):232-6. doi:10.1016/j.jdent.2009.11.002

25. Torres BL, Costa FO, Modena CM, Cota LO, Côrtes MI, Seraidarian PI. Association between personality traits and quality of life in patients treated with conventional mandibular dentures or implant-supported overdentures. J Oral Rehabil. 2011;38(6):454-61. doi:10.1111/j.1365-2842.2010.02165.x

26. Slagter AP, Bosman F, Glas HW, Bilt A. Human jawelevator muscle activity and food comminution in the dentate and edentulous state. Arch Oral Biol. 1993;38(3):195-205. doi:10.1016/0003-9969(93)90028-K

27. Feine JS, Awad MA, Lund JP. The impact of patient preference on the design and interpretation of clinical trials. Community Dent Oral Epidemiol. 1998;26(1):70-4. doi:10.1111/j.1600-0528.1998.tb02086.x

28. Dean AG, Sullivan KM, Soe MM. OpenEpi: open source epidemiologic statistics for public health. 2015 [cited 2015 10 oct]. Avaible from: http://www.OpenEpi.com

29. Jong M, Wright $\mathrm{P}$, Meijer HJA, Tymstra N. Posterior mandibular residual ridge resorption in patients with overdentures supported by two or four endosseous implants in a 10-year prospective comparative study. Int J Oral Maxillofac Implants. 2010;25(6):1168-74. 